\title{
Comparative Study of Dorsal Guard Hair of Large Indian Civet (Viverra zibetha) and Small Indian Civet (Viverricula indica) (Carnivora: Viverridae: Mammalia)
}

\author{
Manokaran Kamalakannan* \\ Zoological Survey of India, M-Block, New Alipore, Kolkata-700053, India \\ *Corresponding author
}

\begin{tabular}{|c|c|}
\hline & A B S T R A C T \\
\hline Keywords & \multirow{4}{*}{$\begin{array}{l}\text { The microscopic hair analysis of Large Indian Civet (Viverra zibetha) and } \\
\text { Small Indian Civet (Viverricula indica) was done using the optical light } \\
\text { microscope for its species identification, the hair of two species showed } \\
\text { different cuticular and cross-section characteristics. The unique cuticular } \\
\text { pattern 'broad diamond petal' and the shape of the cross-section 'oval or } \\
\text { oblong' of dorsal guard hair of two species determine the species identity } \\
\text { between the two species. The high-resolution photo-micrographs and key } \\
\text { characteristics of hair presented here can be used as an appropriate } \\
\text { reference for species identification. }\end{array}$} \\
\hline $\begin{array}{l}\text { Dorsal Guard Hair, } \\
\text { Optical Light } \\
\text { Microscope, } \\
\text { Large Indian Civet, } \\
\text { Small Indian Civet. }\end{array}$ & \\
\hline Article Info & \\
\hline $\begin{array}{l}\text { Accepted: } \\
\text { 12 April } 2017 \\
\text { Available Online: } \\
10 \text { May } 2017\end{array}$ & \\
\hline
\end{tabular}

\section{Introduction}

The hair characteristics study is one of the methods for identification of mammals when the morpho-taxonomy is failed to provide a proper result in the case of small part of the skin of a mammal available (Chakraborty and De, 2010). The tricho-taxonomy i.e. study of mammal hair can be used for identification of species on the basis of a combination of microscopic characters (Teerink, 1991). There are many workers viz., Mayer (1952); Brunner and Coman (1974); Moore et al., (1974); Koppikar and Sabins (1975); Teerink (1991); Wallis (1993); Chakraborty and De (2010) have well documented the different hair characters of mammals.
In India, the significant tricho-taxonomic studies have been carried out by many workers on different species of mammals viz., Koppikar and Sabins (Artiodactyls; 1975); Bahuguna et al., (selected mammals; 2010); Chakraborty and De (Carnivores; 2010); Sarkar (Rodents and Primates; 2012) and Kamalakannan (Artiodactyls and Lagomorphs, 2015). Apart from these studies, Chakraborty and De (2010), Bahuguna (2011) have well documented the hair characters of family Viverridae. However, comparative study of hair characters between Viverra zibetha and Viverricula indica is little known. Therefore, in the present study, the 
microscopic analysis of hairs of Viverra zibetha and Viverricula indica was studied comparatively.

\section{Materials and Methods}

The dorsal guard hairs of were collected from the dry skins of Viverra zibetha and Viverricula indica housed in the National Zoological Collections, Mammal and Osteology Section, Zoological Survey of India, Kolkata, India. The samples were washed thoroughly with acetone and carbon tetrachloride to remove the dirt of exogenous materials. The cuticular characters of hair such as scale position, scale patterns, structure of scale margins and distance between scale margins and medullary characters such as width composition, structure and form of margins of the medulla, and shape of crosssection of hair were examined under $100 \mathrm{X}$ $400 \mathrm{X}$ magnification with help of the digital camera fitted on optical microscope (Olympus BX41) and the observed microscopic characters of hair were photographed. The methodology and nomenclature of cuticular, medullary and cross-sectional characteristics of dorsal guard hairs were followed according to the descriptions provided by Brunner and Comman (1974), Moore et al., (1974) and Teerink (1991).

\section{Results and Discussion}

The general pelage colour of Viverra zibetha is dark hoary grey mixed with yellowish or brown tinge fur; Viverricula indica is tawny grey or greyish brown infused with spots on the body (Menon, 2014) (Table 1 and Fig. $1 \& 2)$. The cuticular characteristics of dorsal guard hair differed between the two species studied i.e. the scale position was 'longitudinal', scale patterns was 'broad diamond petal', the structure of scale margins was 'smooth' and the distance between scale margins- 'distant' was observed in Viverra zibetha, but the scale position was either 'transversal' or 'longitudinal', scale patterns was either 'regular wave' or 'broad diamond petal', the structure of scale margins was 'smooth' and the distance between scale margins- 'distant' was observed in Viverricula indica.

Table.1 Microscopic hair characteristics of Viverra zibetha and Viverricula indica

\begin{tabular}{lll}
\hline Microscopic hair characteristics & Viverra zibetha & Viverricula indica \\
\hline Cuticular scale position & longitudinal & $\begin{array}{l}\text { longitudinal / } \\
\text { Transversal }\end{array}$ \\
\hline Cuticular scale patterns & broad diamond petal & $\begin{array}{l}\text { Regular wave/ broad } \\
\text { diamond petal }\end{array}$ \\
\hline Cuticular Structure of scale margins & Smooth & Smooth \\
\hline Distance between cuticular scale margins & Distant & Distant \\
\hline Composition of medulla & multicellular in rows & multicellular in rows \\
\hline Structure of medulla & wide medulla lattice & wide medulla lattice \\
\hline Margins of medulla & straight & straight \\
\hline Shape of cross-section & Oval & Oval / Oblong \\
\hline
\end{tabular}


Fig.1\&2 Photo-micrograph of hairs of Viverra zibetha and Photo-micrograph of hairs of Viverricula indica

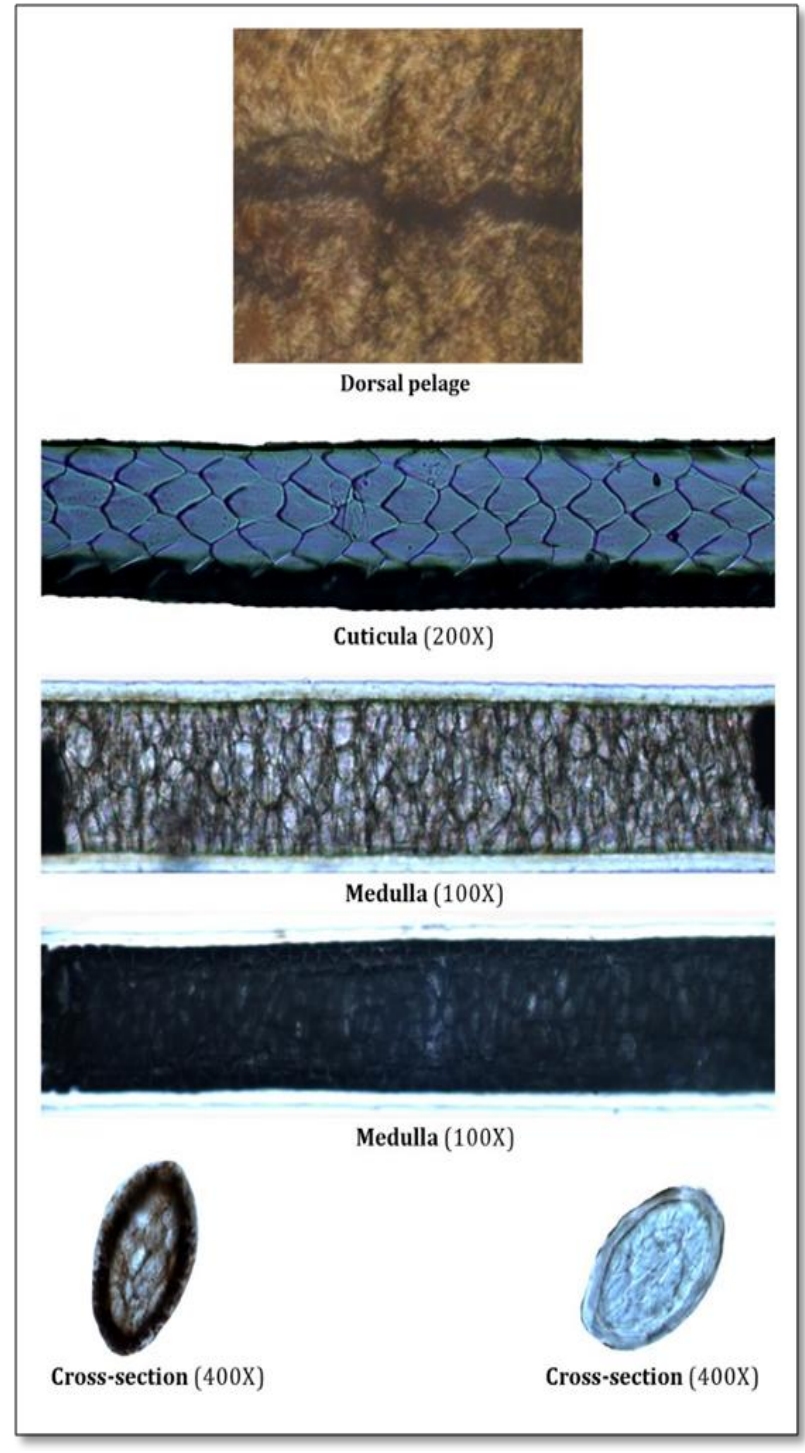

However, the medullary characteristics of dorsal guard hair of the two species studied were similar as: the composition of medulla'multicellular in rows', the structure of medulla- 'wide medulla lattice', and form of the medulla margins- 'straight'. The crosssection of hair was varied between the two species and observed as: 'oval', and 'oval or oblong' shape in dorsal guard hair of Viverra zibetha and Viverricula indica, respectively. As mentioned earlier, the two species Viverra zibetha and Viverricula indica can be

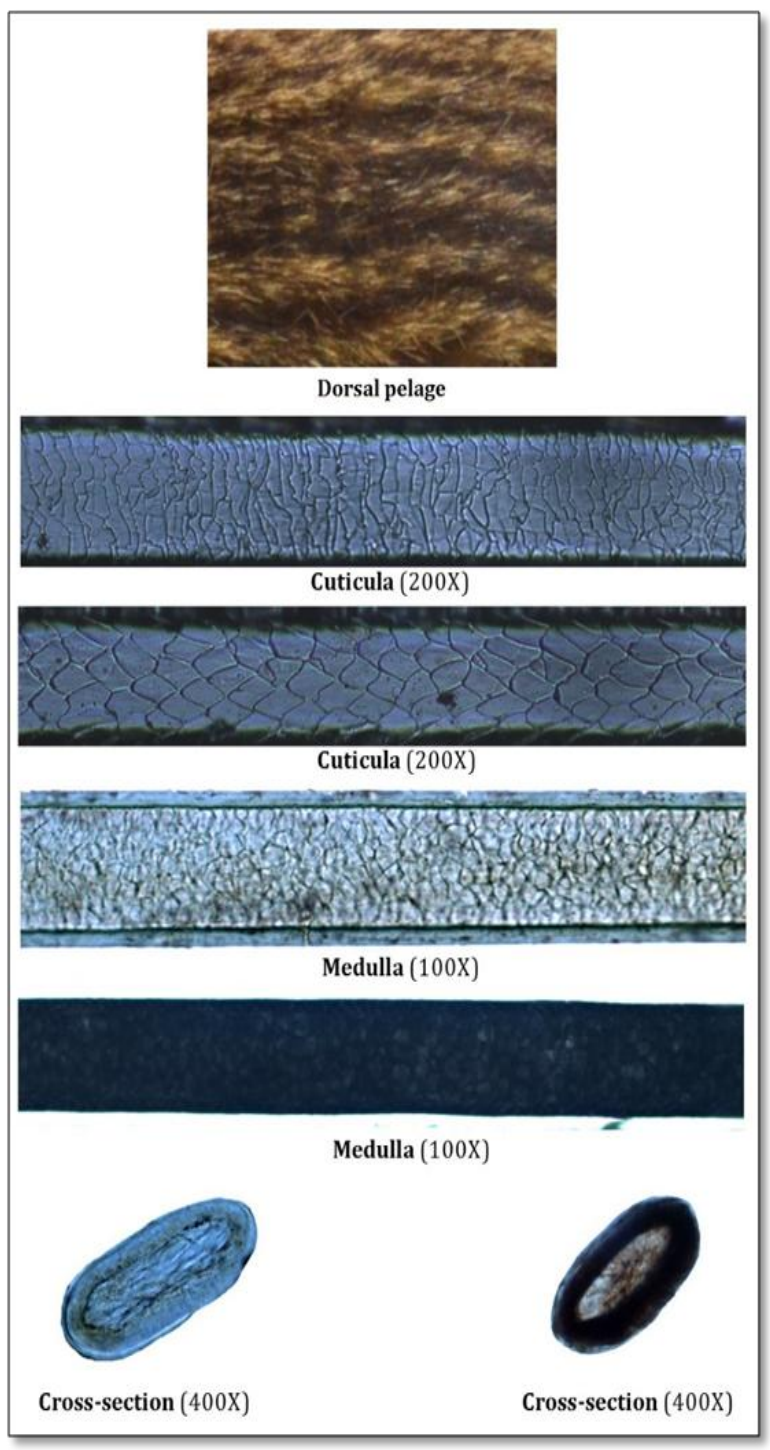

diagnosed with their pelage coat colour (Menon, 2014). Apart from this, the distinct microscopic characters such as 'longitudinal' and 'broad diamond petal (Viverra zibetha)' and 'transversal regular wave or longitudinal' and 'regular wave or broad diamond petal' (Viverricula indica) cuticular scales of hair also determines the species identity between the two species. Although the medullary characteristics of dorsal guard hair are similar between the two species studied, the shape of the cross-section of dorsal guard hair makes 
the distinct between the two species i.e. 'oval' in Viverra zibetha and 'oval or oblong in Viverricula indica. Similar observation was made by Chakraborty and De (2010), and Bahuguna (2011) on dorsal guard hair's study of family Viverridae, however, the hair characters are varied comparatively. This study provides a complete combination of characters of dorsal guard hair of Viverra zibetha and Viverricula indica for species identification.

In conclusion, the two species of civets listed under Schedule II of the Indian Wildlife (Protection) Act, 1972 as they are threatened by many factors including poaching. This animal is poached for local consumption, body parts and glands for medicinal uses. Therefore, the photo-micrographs are presented here can be used in forensic science as well as prey-predator food analysis as an appropriate reference for the species identification.

\section{Acknowledgements}

The author sincerely thanks the Director, Zoological Survey of India, Kolkata for providing necessary facilities.

\section{References}

Bahuguna, A. 2011. Trichotaxonomy of species of the families Sciuridae, Viverridae, Mustelidae, Herpestidae and Tragulidae. Records of the Zool. Survey of India, Occasional Paper331, 121.

Bahuguna, A., Sahajpal, V., Goyal, S.P., Mukherjee, S.K. and Thakur, V. 2010. CD version of forensic guide for identification of selected mammals from primary guard hair. Wildlife Institute of India, Dehradun $438 \mathrm{pp}$.

Brunner, H. and Comman, B. 1974. The Structure of Hairs. Inkata Press, Melbourne, Australia, $170 \mathrm{pp}$.

Chakraborty, R. and De, J.K. 2010. Atlas on hairs Indian Mammals Part- I: Carnivora: Published by the Director, Zoological Survey India, $141 \mathrm{pp}$.

Kamalakannan M. 2015. Tricho-taxonomic studies of Indian mammal species belonging to the orders Artiodactyla and Lagomorpha, Ph.D thesis. University of Kalyani, West Bengal, India.

Koppiker, B.R. and Sabins, J.H. 1975. Identification of hairs of some Indian mammals. J. Bombay Natural History and Society, 73: 5-20.

Mayer, W.V. 1952. The hair of California mammals with keys to the dorsal guard hairs of California mammals. American Midland Naturalist, 38: 480-512.

Menon, V. 2014. Indian mammals- a field guide. Hachette (India) Pvt. Limited. 528 pp.

Moore, T.D., Spence, L.E and Dugnolle, C.E. 1974. Identification of the dorsal guard hairs of some mammals of Wyoming. Game and Fish Department, Wyoming, 177 pp.

Sarkar, P.S. 2012. Tricho-taxonomic study of hairs of Indian mammals: order-Primates and Rodentia, Ph.D thesis, University of Kalyani, Kalyani, West Bengal, India.

Teerink, B.J. 1991. Hair of West-European mammals atlas and identification key. Cambridge: Cambridge University Press, 223 pp.

Wallis, R.L. 1993. A key for the identification of guard hairs of some Ontario mammals. Canadian J. Zool., 71: 587-591.

\section{How to cite this article:}

Manokaran Kamalakannan. 2017. Comparative Study of Dorsal Guard Hair of Large Indian Civet (Viverra zibetha) and Small Indian Civet (Viverricula indica) (Carnivora: Viverridae: Mammalia). Int.J.Curr.Microbiol.App.Sci. 6(5): 1391-1394.

doi: https://doi.org/10.20546/ijcmas.2017.605.150 